\title{
Incidence of lymphatic involvement in differentiated-type intramucosal gastric cancers as examined by endoscopic resection
}

\author{
Yasuko Fujita $\cdot$ Mitsuo Kishimoto \\ Ryuta Nakao $\cdot$ Reiko Kimura-Tsuchiya \\ Nobuaki Yagi $\cdot$ Akio Yanagisawa
}

Received: 19 August 2014/ Accepted: 8 January 2015/Published online: 1 February 2015

(c) The International Gastric Cancer Association and The Japanese Gastric Cancer Association 2015

\begin{abstract}
Background Lymphatic involvement may sometimes be detected in differentiated-type intramucosal cancer resected endoscopically during routine examination, but its incidence and clinical significance remain unknown.

Methods We examined 300 endoscopically resected lesions obtained from 238 patients diagnosed with differentiated-type intramucosal gastric cancer. All sections were subjected to D2-40 monoclonal-based immunohistochemistry.

Results The incidence of lymphatic involvement in differentiated-type intramucosal cancer was $2.0 \%(6 / 300)$. An incidence of $1.8 \%$ (5/279) was determined in lesions that were $\leq 3 \mathrm{~cm}$ in size and $2.2 \%(6 / 276)$ in those without an ulcer or ulcer scar. Of the six lesions presenting lymphatic involvement, three were determined to be histologically mixed with a predominance of differentiated type, while the other three lesions were pure differentiated type. Conclusions We determined that the incidence of lymphatic involvement in differentiated-type intramucosal
\end{abstract}

Y. Fujita $(\varangle) \cdot$ M. Kishimoto $\cdot$ A. Yanagisawa

Department of Pathology, Kyoto Prefectural University of

Medicine, 465, Kajii-cho, Kamigyo-ku, Kyoto-shi,

Kyoto 602-8566, Japan

e-mail: bkm@koto.kpu-m.ac.jp

R. Nakao

Department of Surgical Pathology, Japanese Red Cross Society

Kyoto Daiichi Hospital, Kyoto, Japan

R. Kimura-Tsuchiya

Department of Medical Oncology, Fukushima Medical

University, Fukushima, Japan

N. Yagi

Department of Gastroenterology, Murakami Memorial Hospital,

Asahi University, Gifu, Japan cancer was $2.0 \%$. To clarify the clinical significance of such lymphatic involvement, it is necessary to detect it with this incidence in mind and to gather and follow up the clinical courses of such cases.

Keywords Stomach neoplasm · Adenocarcinoma $\cdot$ D2-40 monoclonal antibody $\cdot$ Gastrointestinal endoscopy

\section{Introduction}

Early gastric cancer (EGC) is commonly defined as a gastric carcinoma in which tumor invasion is confined to the mucosa or submucosa (T1) irrespective of lymph node metastasis. Histologically, gastric adenocarcinomas are classified into several subtypes [1], but they are commonly divided into two major types: differentiated and undifferentiated type, according to the predominant histological structures [2]. Differentiated-type carcinomas comprise dominant components of well or moderately differentiated tubular adenocarcinomas or papillary adenocarcinomas, while undifferentiated-type carcinomas include poorly differentiated adenocarcinomas, signet-ring cell carcinomas or mucinous adenocarcinomas. Recently, mixed-type carcinomas (i.e., composed of both differentiated and undifferentiated type) have attracted much attention [3-5]. Takizawa et al. [3] proposed a classification of lesions into four types according to the proportions of intramucosal differentiated vs. undifferentiated components upon histopathological examination: (1) pure differentiated (PD) type, i.e., composed of differentiated type only, (2) mixed predominantly differentiated (MD) type, i.e., mostly composed of differentiated type, (3) mixed predominantly undifferentiated (MU) type and (4) pure undifferentiated (PU) type (i.e., composed of undifferentiated type only). 
Another classification of gastric cancers was proposed on the basis of the mucin phenotype, in which they are divided into gastric, intestinal, mixed gastric and intestinal, or null (or unclassified) types [6-9].

Endoscopic resection (ER), which includes endoscopic mucosal resection (EMR) and endoscopic submucosal dissection (ESD), is currently a standard treatment for EGC with a negligible risk of lymph node metastasis [10]. The indications for ER for EGC were published by the Japanese Gastric Cancer Association [2]. A number of studies have revealed the incidence of lymph node metastasis in the materials resected by operations, and risk factors for lymph node metastasis have been investigated [11-17]. In these studies, risk factors for lymph node metastasis were defined as tumor size, histological type, ulcerative findings, depth of tumor invasion and lymphovascular invasion.

Similarly, the incidence and significance of lymphatic invasion in EGC were examined in a number of studies [18-22]. However, in differentiated-type cancers, the investigations were conducted without stratification of intramucosal cancers or in cancers where submucosal invasion had occurred. In specimens resected by ER, lymphatic vessel invasion is sometimes observed on daily histological examinations, even in the differentiated-type intramucosal cancers. However, the precise incidence and significance are still unknown. Therefore, it is important to fill this knowledge gap. A greater understanding of the lymphatic involvement in EGC would thus clarify whether patients presenting differentiated-type intramucosal cancers with lymphatic involvement require additional operative treatment. Here, we evaluated the incidence of lymphatic vessel invasion in differentiated-type intramucosal cancers resected by ER. Here we performed immunohistochemical staining, based on D2-40 monoclonal antibody binding, which allows for a high binding specificity to the endothelium of lymphatic vessels.

\section{Methods}

We examined 300 lesions obtained from 238 patients who underwent endoscopic resection for differentiated-type intramucosal gastric cancer at the Hospital of Kyoto Prefectural University of Medicine (Kyoto, Japan) between September 2011 and February 2014. To analyze the incidence of lymphatic involvement in these lesions, we included patients presenting plural lesions synchronously or metachronously.

The endoscopically resected materials were fixed in 10 or $20 \%$ buffered formalin. They were cut into 2-mm-thick specimens, processed for paraffin embedding and sliced into $3-\mu \mathrm{m}$-thick sections. All sections were subjected to H\&E and D2-40 immunohistochemical staining. The sections were then examined by a pathologist, Y.F., who determined the histological type, depth of invasion and lymphatic involvement. The same sections were examined by other pathologists (A.Y., M.K. and R.N.), and in case of conflict, a consensus was reached. We divided differentiated-type intramucosal gastric cancer into two histological subtypes: pure differentiated (PD) and mixed predominantly differentiated (MD) type, as previously described [3-5].

Immunohistochemistry

Mouse monoclonal antibody against human lymphatic endothelium antigen, D2-40 (Nichirei, Tokyo, Japan), was applied to all 3- $\mu$ m-thick paraffin sections. According to a previously described procedure, lymphatic involvement commonly appears as cancer cell nests surrounded by D240 positively stained lymphatic endothelium. Furthermore, we analyzed the immunohistochemistry of p53 (DO-7, dilution 1:50; Dako, Glostrup, Denmark), Muc-2 glycoprotein (Ccp58, dilution 1:20; Novocastra, Newcastle, UK), Muc-5AC glycoprotein (CLH2, dilution 1:100; Novocastra), Muc-6 glycoprotein (CLH5, dilution 1:100; Novocastra), CD10 (56C6, dilution 1:40, Novocastra), pepsinogen I [8003 (99/12), dilution 1:100; AbD Serotec, Oxford, UK] and $\mathrm{H}^{+}, \mathrm{K}^{+}$-ATPase (dilution 1:1,000; Calbiochem, Darmstadt, Germany) of the sections with lymphatic involvement. The lesions were regarded as showing positive expression when more than $10 \%$ of tumor cells were positive for Muc-2, Muc-5AC, Muc-6, CD10, pepsinogen $\mathrm{I}$ and $\mathrm{H}^{+}, \mathrm{K}^{+}$-ATPase.

\section{Statistical analysis}

Statistical analysis for the comparison of clinicopathological features was performed using StatView software (version 5.0; StatView, SAS Institute Inc., Cary, NC, USA). To determine the presence of significant differences in age and tumor size, the Mann-Whitney $U$ test was used. The Fisher's exact test and chi-square test were used to compare other clinicopathological features. $P$ values of less than 0.05 were considered to indicate statistical significance.

The probability of lymph node metastasis was estimated with a $95 \%$ confidence interval (95\% CI) based on binomial distribution using the statistical computing software R, version 3.1.2 (R Foundation for Statistical Computing, Vienna, Austria).

\section{Results}

Patient profiles and histological characteristics of the lesions are summarized in Table 1, which compares lesions with vs. lesions without lymphatic involvement. 
Table 1 Incidence of lymphatic involvement in the different types of gastric cancers

\begin{tabular}{|c|c|c|c|}
\hline & \multicolumn{2}{|c|}{ Lymphatic involvement } & \multirow[t]{2}{*}{$P$ value } \\
\hline & Present $(n=6)$ & Absent $(n=294)$ & \\
\hline \multicolumn{4}{|l|}{ Age (years) } \\
\hline Median (range) & $70.5(47-81)$ & $71(42-92)$ & $\mathrm{NS}^{\mathrm{a}}$ \\
\hline \multicolumn{4}{|l|}{ Gender } \\
\hline Male & $4(1.7 \%)$ & 231 & $N S^{b}$ \\
\hline Female & $2(3.1 \%)$ & 63 & \\
\hline \multicolumn{4}{|l|}{ Location } \\
\hline Upper & $1(2.2 \%)$ & 44 & $\mathrm{NS}^{\mathrm{c}}$ \\
\hline Middle & $2(2.0 \%)$ & 97 & \\
\hline Lower & $3(2.0 \%)$ & 144 & \\
\hline \multicolumn{4}{|l|}{ Macroscopic type } \\
\hline Elevated & $4(3.3 \%)$ & 117 & $\mathrm{NS}^{\mathrm{c}}$ \\
\hline Flat & 0 & 23 & \\
\hline Depressed & $1(0.8 \%)$ & 131 & \\
\hline Mixed & $1(4.2 \%)$ & 23 & \\
\hline \multicolumn{4}{|l|}{ Tumor size (mm) } \\
\hline$\leq 30$ & $5(1.8 \%)$ & 274 & $\mathrm{NS}^{\mathrm{b}}$ \\
\hline$>30$ & $1(0.5 \%)$ & 20 & \\
\hline Median (range) & $28(9-69)$ & $11(0.5-85)$ & \\
\hline \multicolumn{4}{|l|}{ Histological type } \\
\hline PD type & $3(1.0 \%)$ & 283 & $0.015^{\mathrm{b}}$ \\
\hline MD type & $3(21.4 \%)$ & 11 & \\
\hline Post-operated stomach & $1(10 \%)$ & 9 & $N S^{b}$ \\
\hline \multicolumn{4}{|l|}{ Vascular involvement } \\
\hline Absent & $6(2.0 \%)$ & 294 & \\
\hline Present & $0(0 \%)$ & 0 & \\
\hline \multicolumn{4}{|l|}{ Ulcer or ulcer scar } \\
\hline Absent & $6(2.1 \%)$ & 270 & $N S^{b}$ \\
\hline Present & $0(0 \%)$ & 24 & \\
\hline
\end{tabular}

$P D$ pure differentiated, $M D$ mixed predominantly differentiated, NS nonsignificant

${ }^{\text {a }}$ Mann-Whitney $U$-test

${ }^{\mathrm{b}}$ Fisher's exact test

c Chi-square test \begin{tabular}{ll} 
Lymphatic involvement & \\
\hline Present $(n=6)$ & Absent $(n=294)$
\end{tabular}

$0.5(47-81)$

$1(2.2 \%)$

97

Table 2 Clinicopathological characteristics of six patients presenting differentiated intramucosal gastric cancer with lymphatic involvement

\begin{tabular}{|c|c|c|c|c|c|c|c|c|c|c|c|}
\hline & Sex & Age & Location & $\begin{array}{l}\text { Macroscopic } \\
\text { type }\end{array}$ & $\begin{array}{l}\text { Tumor } \\
\text { size } \\
(\mathrm{mm})\end{array}$ & $\begin{array}{l}\text { Histological } \\
\text { type }\end{array}$ & $\begin{array}{l}\text { Vascular } \\
\text { invasion }\end{array}$ & $\begin{array}{l}\text { Ulcer } \\
\text { or } \\
\text { ulcer } \\
\text { scar }\end{array}$ & $\begin{array}{l}\text { Additional } \\
\text { operation/ } \\
\text { lymph } \\
\text { node } \\
\text { metastasis }\end{array}$ & $\begin{array}{l}\text { Tumor } \\
\text { recurrence }\end{array}$ & $\begin{array}{l}\text { Follow-up } \\
\text { period } \\
\text { (years) }\end{array}$ \\
\hline Case 1 & M & 66 & Antrum & $0-$ IIc & 69 & MD & - & - & \pm & - & 2 \\
\hline Case 2 & $\mathrm{~F}$ & 47 & Lower corpus & 0-IIa & 9 & PD & - & - & - & - & 1.4 \\
\hline Case 3 & M & 72 & Pyloric antrum & 0-Ip & 28 & MD & - & - & \pm & - & 1.2 . \\
\hline Case 4 & M & 69 & Antrum & 0-IIa + IIc & 24 & MD & - & - & \pm & - & 0.7 \\
\hline Case 5 & M & 73 & $\begin{array}{l}\text { Cardia (remnant } \\
\text { stomach) }\end{array}$ & $0-\mathrm{I}$ & 29 & PD & - & - & - & - & 0.3 \\
\hline Case 6 & $\mathrm{~F}$ & 81 & $\begin{array}{l}\text { Lower corpus to } \\
\text { angle }\end{array}$ & 0-IIa & 28 & PD & - & - & - & - & 0.1 \\
\hline
\end{tabular}

The incidence of lymphatic involvement in differentiated-type intramucosal cancer was $2.0 \%$ (6/300). The incidence was $1.8 \%(5 / 279)$ in those that were $\leq 3 \mathrm{~cm}$ in size and $2.2 \%(6 / 276)$ in those without an ulcer or ulcer scar.
Of the six patients who presented differentiated-type intramucosal gastric cancer with lymphatic involvement, four were male and two female (Table 2). Their median age was 70.5 years (range $47-81$ years). The median size 
Table 3 Histological and immunohistochemical details of six patients presenting differentiated intramucosal gastric cancer with lymphatic involvement

\begin{tabular}{|c|c|c|c|c|c|c|c|c|c|}
\hline & \multirow{2}{*}{$\begin{array}{l}\text { Histological } \\
\text { type }\end{array}$} & \multirow{2}{*}{$\begin{array}{l}\text { Details of histological } \\
\text { components }\end{array}$} & \multicolumn{7}{|c|}{ Immunohistochemistry } \\
\hline & & & p53 overexpression & Muc-2 & Muc-5AC & Muc-6 & CD10 & Pepsinogen I & $\begin{array}{l}\mathrm{H}^{+} \\
\mathrm{K}^{+-} \text {ATPase }\end{array}$ \\
\hline Case 1 & MD & tub2 $>$ por2 & + & - & - & + & - & - & - \\
\hline Case 2 & PD & tub2 $>$ tub1 & - & - & + & + & - & - & - \\
\hline Case 3 & MD & tub $2>$ tub $1>$ por 2 & + & - & + & - & + & - & - \\
\hline Case 4 & MD & tub2 $>$ tub $1>$ por $2>\operatorname{sig}$ & + & - & + & + & - & - & + \\
\hline Case 5 & PD & tub1 $>$ tub2 & + & - & - & - & + & - & - \\
\hline Case 6 & PD & tub1 > pap & - & - & + & + & - & - & + \\
\hline
\end{tabular}

$P D$ pure differentiated, $M D$ mixed predominantly differentiated, $t u b 1$ well-differentiated tubular adenocarcinoma, $t u b 2$ moderately differentiated tubular adenocarcinoma, pap papillary adenocarcinoma, por2 poorly differentiated adenocarcinoma (non-solid type), sig signet-ring cell carcinoma

of the tumors was $28 \mathrm{~mm}$ (range 9-69 $\mathrm{mm}$ ), and the numbers of tumors located in the upper, middle and lower stomach were 1, 2 and 3 , respectively. The numbers of tumors that were elevated, flat, depressed and mixed with any of the macroscopic types were $4,0,1$ and 1 , respectively. There were no vascular invasions and no ulcers in the six lesions presenting lymphatic involvement.

Three of the six lesions with lymphatic involvement present were defined as MD type, while the other three lesions were PD type. In contrast, most of the lesions without lymphatic involvement were PD type. MD type lesions were significantly more frequent in lesions with lymphatic involvement present (Table 1).

Table 3 shows the details of the histological components and immunohistochemistry results for the six lesions with lymphatic involvement. Four of the six lesions were moderately differentiated tubular adenocarcinoma as the dominant component and one contained a minor component of papillary carcinoma. Four of the six lesions demonstrated clear p53 overexpression, and four lesions had a gastric-type mucin phenotype, i.e., positive for Muc-5AC and/or Muc-6 and negative for Muc-2 and CD10.

Although additional operations with lymphadenectomy were performed in three patients, no lymph node metastasis was observed in any of them $(0 / 3 ; 95 \%$ CI, 0-70.8\%). The other three patients were kept under careful monitoring, and to date, no tumor recurrence or metastasis has been clinically detected.

\section{Discussion}

Nowadays, lymphatic involvement is an indication factor for additional surgery in any type of lesions. There has been no previous report in which differentiated-type intramucosal gastric cancers were examined for lymphatic involvement. In the present study, we established that lymphatic involvement in differentiated-type intramucosal gastric cancer occurs at a frequency of $2.0 \%$ and that differentiated-type intramucosal gastric cancers with lymphatic involvement were detected in groups of patients presenting no lymph node metastasis in line with the previous study reported by Gotoda et al. [11].

In intramucosal cancers, lymph node metastasis was reported to be much less frequent, ranging from 1.9-3.3 \%, compared to those in submucosal cancers, about 16.3-20.9\% [11-15, 23]. A number of studies reported the incidence of lymphatic involvement in intramucosal cancers and cancers that involved submucosal invasion altogether. Other reports showed lymph node metastasis in patients who had intramucosal gastric cancer $[3,4,13,14$, 24]. Some authors suggested that lymphatic involvement was a risk factor for lymph node metastasis, but these studies evaluated lymphatic involvement irrespective of other risk factors, such as histological types (differentiated vs. undifferentiated), presence/absence of ulcer or tumor size. Therefore, it remains unknown whether lymphatic involvement is a risk factor for lymph node metastasis in patients who had differentiated-type intramucosal gastric cancers.

Gotoda et al. [11] reported the incidence of differentiated-type intramucosal cancer in detail. According to the study, the incidences of lymph node metastasis in lesions with sizes over $3 \mathrm{~cm}, 3 \mathrm{~cm}$ or less, and in which there was no ulcer, were $1.7 \%$ (7/417), $0 \%(0 / 1230)$ and $0 \%(0 /$ 929), respectively. Regardless of lymphatic involvement, there was no lymph node metastasis in these last two groups. In our present study, the incidences of lymphatic involvement in the last two groups were 1.8 and $2.2 \%$, respectively. Therefore, also in the groups reported by Gotoda et al., there might have been cases where lymphatic involvement occurred without lymph node metastasis. However, the number of such cases might have been small. Whether lymphatic involvement in differentiated-type 
intramucosal cancer represents a risk factor for lymph node metastasis must be further investigated.

The surgically resected materials were sectioned into 5-6-mm-thick specimens, whereas the endoscopically resected materials were cut into half to one-third of the thickness of the operated materials. The numbers of foci with lymphatic involvement detected by $\mathrm{H} \& \mathrm{E}$ staining and by D2-40 monoclonal-based immunohistochemical staining were different $[18,20,21]$. Jeon et al. [18] reported lymphatic involvement in cancers resected by ER. They investigated the incidence on H\&E-stained and immunohistochemical-stained sections. The latter incidence was $4 \%$, which was ten times that of the former, i.e., $0.4 \%$. However, all lesions with lymphatic involvement were in expanded indications. Nine of the 11 lesions were differentiated-type cancers, but the depths of all 11 lesions with lymphatic involvements were M3 + SM1. Therefore, the incidence of lymphatic involvement in differentiated-type intramucosal cancer was not taken into consideration.

In our study, the incidence of lymphatic involvement was associated with the maximum rate during the pathological examination. In routine examination, it may be practically difficult for all serial sections to undergo immunohistochemical staining using D2-40 antibody. Upon daily examination, the degree of lymphatic involvement in differentiated-type intramucosal cancers might thus be lost.

More than half of the lesions with lymphatic involvement had moderately differentiated tubular adenocarcinoma as a dominant component, showing clear p53 overexpression and had a gastric-type mucin phenotype. Koseki et al. [7] reported the correlation between a gastrictype mucin phenotype and lymph node metastasis as well as the high incidence rate of lymphatic involvement with a gastric-type mucin phenotype in differentiated EGC. Our results on the mucin phenotype are in line with this report.

Our study also demonstrated that lymphatic involvement was far more frequent in MD-type tumors than in PD-type tumors. Therefore, pathologists should more carefully investigate lymphatic involvements in cases of differentiated-type intramucosal gastric cancers presenting an undifferentiated-cancer component. The importance of mixed-histologic-type gastric cancer has recently gained much attention in Japan. The prevalence of lymph node metastasis in differentiated-type-predominant mixed type EGC was higher than that in pure differentiated-type EGC $[3,5]$. Takizawa et al. [3] reported that 4 out of 130 patients with PD-type intramucosal gastric cancer had lymph node metastasis, while 6 out of 54 patients with MD-type intramucosal gastric cancers presented lymph node metastasis. The authors examined operated materials collected in previous years when ER had been widely accepted as a common treatment for EGCs. Half of the differentiated- type cancer lesions showed the presence of ulceration, and the mean tumor size was larger than $30 \mathrm{~mm}$. Therefore, the possibility that many of these cancers were not suitable for ER treatment cannot be ruled out.

It is important to determine whether lymphatic involvement is a risk factor for lymph node metastasis. To confirm this, additional cases should be gathered, and the outcome of additional operations or the post-ER course in such cases should be examined. Overall, we recommend that a careful examination for lymphatic involvement be conducted in patients with differentiated-type intramucosal gastric cancers in order to accumulate many more cases.

\section{References}

1. Association Japanese Gastric Cancer. Japanese classification of gastric carcinoma: 3rd English edition. Gastric Cancer. 2011;14:101-12.

2. Japanese Gastric Cancer Association. Japanese gastric cancer treatment guidelines 2010 (ver.3). 2011;14:113-23.

3. Takizawa K, Ono H, Kakushima N, Tanaka M, Hasuike N, Matsubayashi $\mathrm{H}$, et al. Risk of lymph node metastasis from intramucosal gastric cancer in relation to histological types, how to manage the mixed histological type for endoscopic submucosal dissection. Gastric Cancer. 2013;16:531-6.

4. Takizawa K, Kawata N, Tanaka M, Kakushima N, Imai K, Matsubayashi $\mathrm{H}$, et al. Treatment for intramucosal gastric cancer with mixed type histology (differentiated and undifferentiated). Stomach Intestine. 2013;48:1567-79 (in Japanese; abstract in English).

5. Hanaoka N, Tanabe S, Mikami T, Okayasu I, Saigenji K. Mixedhistologic-type submucosal invasive gastric cancer as a risk factor for lymph node metastasis. Endoscopy. 2009;41:427-32.

6. Koseki K, Takizawa T, Koike M, Ito M, Nihei Z, Sugihara K. Distinction of differentiated type early gastric carcinoma with gastric type mucin expression. Cancer. 2000;89:724-32.

7. Tajima Y, Shimoda T, Nakanishi Y, Yokoyama N, Tanaka T, Shimizu K, et al. Gastric and intestinal phenotypic marker expression in gastric carcinomas and its prognostic significance: immunohistochemical analysis of 136 lesions. Oncology. 2001;61:212-20.

8. Yao T, Utsunomiya T, Oya M, Nishiyama K, Tsuneyoshi M. Extremely well-differentiated adenocarcinoma of the stomach: clinicopathological and immunohistochemical features. World J Gastroenterol. 2006;12:2510-6.

9. Namikawa T, Hanazaki K. Mucin phenotype of gastric cancer and clinicopathology of gastric-type differentiated adenocarcinoma. World J Gastroenterol. 2010;16:4634-9.

10. Gotoda T. Endoscopic resection of early gastric cancer. Gastric Cancer. 2007;10:1-11.

11. Gotoda T, Yanagisawa A, Sasako M, Ono H, Nakanishi Y, Shimoda $\mathrm{T}$, et al. Incidence of lymph node metastasis from early gastric cancer: estimation with a large number of cases at two large centers. Gastric Cancer. 2000;3:219-25.

12. Sano T, Kobori O, Muto T. Lymph node metastasis from early gastric cancer: endoscopic resection of tumor. $\mathrm{Br} \mathrm{J}$ Surg. 1992;79:241-4.

13. Yamao T, Shirao K, Ono H, Kondo H, Saito D, Yamaguchi H, et al. Risk factors for lymph node metastasis from intramucosal gastric carcinoma. Cancer. 1996;77:602-6. 
14. Haruta H, Hosoya Y, Sakuma K, Shibusawa H, Satoh K, Yamamoto $\mathrm{H}$, et al. Clinicopathological study of lymph-node metastasis in 1389 patients with early gastric cancer: assessment of indications for endoscopic resection. J Dig Dis. 2008;9:213-8.

15. Maehara Y, Orita H, Okuyama T, Moriguchi S, Tsujitani S, Korenaga D, et al. Predictors of lymph node metastasis in early gastric cancer. Br J Surg. 1992;79:245-7.

16. Hirasawa T, Gotoda T, Miyata S, Kato Y, Shimoda T, Taniguchi $\mathrm{H}$, et al. Incidence of lymph node metastasis and the feasibility of endoscopic resection for undifferentiated-type early gastric cancer. Gastric Cancer. 2009;12:148-52.

17. Gotoda T, Sasako M, Ono H, Katai H, Sano T, Shimoda T. Evaluation of the necessity for gastrectomy with lymph node dissection for endoscopic submucosal dissection of early gastric cancer. Br J Surg. 2001;88:444-9.

18. Jeon SR, Cho JY, Bok GH, Lee TH, Kim HG, Cho WY, et al. Dose immunohistochemical staining have a clinical impact in early gastric cancer conducted endoscopic submucosal dissection. World J Gastroenterol. 2012;18:4578-84.

19. Liu C, Zhang R, Lu Y, Li H, Lu P, Yao F, et al. Prognostic role of lymphatic vessel invasion in early gastric cancer, a retrospective study of 188 cases. Surg Oncol. 2010;19:4-10.
20. Yonemura Y, Endou Y, Tabachi K, Kawamura T, Yun HY, Kameya $\mathrm{T}$, et al. Evaluation of lymphatic invasion in primary gastric cancer by a new monoclonal antibody, D2-40. Hum Pathol. 2006;37:1193-9.

21. Sako A, Kitayama J, Ishikawa M, Yamashita H, Nagawa $H$. Impact of immunohistochemically identified lymphatic invasion on nodal metastasis in early gastric cancer. Gastric Cancer. 2006;9:295-302.

22. Kim JH, Park SS, Park SH, Kim SJ, Mok YJ, Kim CS, et al. Clinical significance of immunohistochemically-identified lymphatic and, or blood vessel tumor invasion in gastric cancer. J Surg Res. 2010;162:177-83.

23. Korenaga D, Haraguchi M, Tsujitani S, Okamura T, Tamada R, Sugimachi K. Clinicopathological features of mucosal carcinoma of the stomach with lymph node metastasis in eleven patients. $\mathrm{Br}$ J Surg. 1986;73:431-3.

24. Ren G, Cai R, Zhang WJ, Ou JM, Jin YN, Li WH. Prediction of risk factors for lymph node metastasis in early gastric cancer. World J Gastroenterol. 2013;19:3096-107. 